\title{
THE EDUCATIONAL COURSE IN THE ACQUISITION OF THE AUTONOMY OF ASSOCIAZONE ITALIANA PERSONE DOWN
}

\author{
Anna Contardi \\ Associazione Italiana Persone Down, Rome, Italy
}

\begin{abstract}
The Associazione Italiana Persone Down is an association of families which acts as a reference point for the parents of children and adults affected by Down syndrome.

To stimulate and sustain the growth of the autonomy of persons with Down syndrome, the first educational course aimed at developing a capacity for autonomy was introduced in the AIPD in Rome in 1989. The course, which was designed for boys and girls from 15 to 20 years, has been repeated every year with an ever greater participation and replicated in many other cities. The educational objectives proposed by the programme are grouped into five areas: communication, orientation, road behaviour, using money, shopping and more generally making use of services.

All the youngsters involved exhibit change; at the end of the course all are able to cross roads by themselves, use a public telephone, ask information in order to resolve their difficulties and know how to go shopping. Furthermore, there are aspects of each persons personality, such as confidence in self, self-esteem, and the capacity to establish relations with others, which have undergone great changes in the direction of a greater knowledge. There is also structural development of their own identities, first and foremost as adolescents, and then as adolescents with certain limitations but nevertheless as adolescents able to do a wide variety of things.
\end{abstract}

Keywords: Down syndrome, adolescence

\section{Introduction}

In his development towards a state of autonomy, an infant with a disability encounters two types of difficulty. On the one hand there is the difficulty represented by the child's disability and on the other, attitudes of fear and the ambivalence of the environment which interfere with the attainment of the level of his or her potential autonomy, although this can nevertheless be reached notwithstanding the disadvantages of the situation. Very frequently parents, but also people in general who meet the child with a disability, develop a protective and solicitous attitude towards the child that hinders his acquisition of independence.

It almost seems as if people want to compensate for the unease created by the disability by means of heightened affection and more permissive attitudes, or that the child is held to be generally incapable and thus in need of help and of someone who stands in for him on every occasion.

An idea has gained ground in recent years, among workers who deal with children with 
developmental disabilities, namely the conviction, espoused with increasing strength, of the importance of educating these children to be autonomous as part of their personal development and their integration into society.

For these reasons, in dealing with families, the theme of developing the capacity of the child's independence is introduced very early on in the relations with the parents.

Many conquests, however, in the community field of independence are difficult to reach in the family environment above all when this problem is dealt with during adolescence; that is, the moment when adolescents with disabilities, just like ordinary adolescents, begin to express a desire to detach themselves from their parents and express irritation at parental attitudes. At the same time it is also difficult for parents to recognise and accept that their children are becoming adult. They must be helped in this process.

The theme, therefore, of educating children to develop their autonomy is a matter of particular importance in adolescence.

\section{The educational course}

The Associazione Italiana Persone Down (AIPD) is an association of families which acts as a reference point for the parents of children and adults affected by Down syndrome.

To stimulate and sustain the growth of the autonomy of persons with Down syndrome, the first educational course aimed at developing a capacity for autonomy was introduced in the AIPD in Rome in 1989. The course, that was designed for boys and girls from 15 to 20 years, has been repeated every year with an ever greater participation and replicated in many other cities.

In order to face the problem of autonomy it is necessary to present oneself as educator not only the objective of teaching some skills, but also that of recognising and favouring the change from child to that of adolescent and then adult. It therefore means creating a feeling and a way of relating oneself to others, a mentality of trust and of respect towards the adolescent. It is in such a climate that the adolescent may find greater motivation to learn and may grow as a person in an ever more global manner.

The programme of the course has kept account of these premises and has, therefore, at the same time developed its actions and turned its attention in this direction.

\section{The structure of the course}

The educational course for the acquisition of autonomy, takes place in moments of free time and takes the form of a series of afternoon meetings (of about 3 hours each).

Each adolescent meets up, once a week, with a group comprising 8-9 persons with Down syndrome and 3-4 social workers. After a joint session the group divides up into sub-groups of 2-3 persons with Down syndrome plus a social worker and a volunteer worker.

It is possible to group the educational objectives proposed by the programme into five areas:

- communication

- orientation

- road behaviour

- using money

- shopping and more generally making use of services.

\section{Communication}

This is the capacity to express one's own needs, desires, and thoughts, not only among the persons familiar to us and who know us, but also in the ambit of strangers. It is essential to develop the capacity to ask information, explain what you need in shops and offices, provide personal information, use the public telephone, both as a means for communicating with whoever you wish to speak to and for calling for help in cases of difficulty. Possessing these abilities along with any strategies for getting round personal language difficulties are objectives to be pursued.

\section{Orientation}

It often happens that adolescents with Down syndrome are used to being guided by their parents or by others in order to reach particular places. This means that they may pay very little attention to the route taken, to reference points, or to the street names. It is therefore, necessary that they increase their capacity to look consciously about themselves in order to learn and follow street signs, identify reference points, recognise bus-stops, taxi-ranks, underground stations, ..

\section{Street behaviour}

The acquisition of adequate behaviour patterns enabling the young people to move around by themselves and paying due attention to road vehicles and pedestrian signs, is fundamental for external autonomy.

\section{The use of money}

The objective in this context is to enable the 
adolescent to make use of money in order to make purchases by themselves. This means they must go through various phases: understanding the meaning and the use of money as a means of exchange, recognising the various denominations of bank notes and coins, counting them, understanding the approximate value of the most commonly used articles, reading the prices, providing the money requested, understanding when change has to be received and how to count it.

\section{The use of services}

It is necessary to learn how to recognise and make adequate and familiar use of shops and the most commonly used services.

This is a question of identifying shops which are useful for the purchase of various products as well as understanding how to make use of markets and supermarkets, and knowing how to use the principle public offices such as the postoffice, transport services and the most common forms of entertainment such as bowling, cinema, fun-fairs, fast-food restaurants, etc.

The activities proposed to the young people cover all the foregoing areas and concentrate on those interests which are typical of their agegroup (going to the cinema or the sandwich-bar), calendar events (Christmas lists and shopping) or daily occurrences (personal purchases) and are sometimes organised in exploration quests (such as a market study to identify the most economic shop).

The psychological climate chosen for the objectives proposed by the course is a recreational and gratifying social ambit in which the adolescents feel themselves to be protagonists and thus their feeling of no longer being children but "grown-up" is reinforced.

For this reason, as a vehicle for this experience, the "Teenagers' Club" (Club dei ragazzi) has been created which the course participants belong to, and duly receive a badge and membership card. This climate helps the boys and girls to identify themselves as adolescents, stimulates communication and creates bonds of friendship inside the group.

\section{The principles and the methodology of work}

In the design of the course-project and in the choice of the ways to carry out the activities, certain principles have been identified which underlie the entire manner of our work.

\section{A relationship based upon "truth"}

Great weight has been attached to motivation as a stimulus for all learning activity, in the conviction that this will be the best motor for a type of teaching which is based upon and remains a practical activity. This means, for example, counting money in order to eat at a fast-food restaurant, using the telephone to contact an absent friend, asking information in order to reach a place chosen for the afternoon's activities,,..

However, the boys and girls are very sensitive to the matter of real and not fictitious motivations. None of them are happy to go and buy milk, for example, if there is already milk in the fridge or if they all know that their mother would go if they didn't.

At the same time this form of relationship reinforces the boys and girls conviction of being responsible teenagers and worthy of the trust that adults give them.

\section{The active involvement of the boys and girls in the choice and running of the activities.}

This choice also is aimed at providing an incentive to the youngsters to behave correctly and responsibly, thus enhancing their role as protagonists.

In addition to stimulating various types of minor concerns in the course of the co-management by the youngsters of the choices on what to eat for lunch or how to organise the week-end, this has led to the choice of working together in small fixed groups (8-9 boys and girls a day) with occasional further sub-divisions.

In order to further exploit student responsibility, every year two very important activities are included in the course. The first is the drawing up of a "set of rules" for the club. These are approved by all the members and act as a means of reinforcing the sense of belonging to the club and shifting judgements about good and bad conduct from the figure of the adult educator to the group, that is to the youngsters themselves. Second, after the first months the teenagers are given a short-list of highly practical personal objectives which have to be reached through such as actions as taking one's own group to the cinema (areas: communication, orientation, use of money and services), making a telephone call. etc. The achievement of these objectives is viewed as becoming quick-witted and capable, that is more mature and responsible. 


\section{Consideration of their "no longer being children" and the explicit discussion of this role change as a reinforcement for the acquisition of additional independence.}

This is made possible also by the manner in which the educators address the young people in the language used, in the type of activity, appropriate for teenagers, which are proposed as a way of passing the afternoon (cinema, discotheque, bowling, fast-food, etc.), and in their advice on how to dress.

\section{Personalised strategies}

For each boy or girl, individual strategies are identified to make them autonomous, which are based on their specific resources. For example, if a boy is able to read he is encouraged to do so by having him recognise the products in a shop. If he cannot read he is encouraged to recognise the image of the product or the writing which appears on the box containing the article. And if he has a good language skills he is encouraged to get the others to help him by asking them questions etc.

Every skill to be acquired is seen not in terms of the skill itself and by itself, but only in relation to the ultimate objective of autonomy and, therefore, it is chosen in relation to this objective, as also in relation to the capacities or difficulties of the individual boy or girl.

The methodology of work is globally characterised by a design approach whereby each project is designed solely with reference to the objectives, the analysis of the situation (the environment and the personnel) and the resources.

In carrying out of the activities certain "instruments" are also made use of in order to facilitate the performance of certain tasks and to act as means for reaching the chosen objectives of autonomy.

With the exception of the portfolio which has been studied and realised especially for the youngsters, in choosing the instruments it has been noted that it is possible, with a minimum of creativity and with accurate observation of the teenagers and their difficulties, to find an endless number of "normal" instruments (for example, the money-belt) which can facilitate the achievement of a certain level of autonomy.

\section{The staff}

The work group which has designed and conducted the development experience in these years comprises a co-ordinating social worker who directs the course (A. Contardi) and 3-4 educators every year who directly follow the youngsters with a ratio of course-participants to educators of 2:1 or 3:1 as well as maintaining relations with the young people's families. The group is also flanked by a large number of young volunteers (17-30 years old).

\section{The youngsters - the results}

None of youngsters who participated in the course over these years underwent a selection test of any kind, except for that of age: they had to be between 15 and 20, the families had to explicitly accept the objectives of the course and the ways they were realised.

All the participants were placed in a course structured over three years, in which the first year is generally dedicated to the discovery of the first types of autonomy and also that of feeling himself to be grown up. The second year is taken up with the acquisition of additional skills and the third with their consolidation. General and personal objectives are fixed for each of the participants. At the beginning of the course and subsequently, at least two times every year, evaluations are made of the changes in the youngsters by making use of specially drawn up structured observation grids, which are compiled during the sessions.

The youngsters who participated in the Rome courses were employed in the mornings in various educational and occupational activities.

As regards the level of autonomy at the beginning of the course we were presented with a great variability which did not however appear correlated with the higher or lower scholastic levels attained. Right from our initial conversations, we understood that often the absence of capacity, in the sense of autonomy, was related to the scarce or complete lack of opportunities offered in the past. The parents often replied to our questions with expression such as "I don't know, we never tried". Even where such ability existed it was often present in only a haphazard fashion the result more of casual experience than of any precise educational objective.

It is interesting to consider some of the data on the skills acquired by the youngsters which we have identified as significant signposts on their path to autonomy. 


\begin{tabular}{|c|c|c|c|c|c|}
\hline \multirow{2}{*}{$\begin{array}{l}\text { Ability } \\
\text { Crossing roads by oneself }\end{array}$} & \multirow[b]{2}{*}{ Yes } & \multicolumn{2}{|c|}{ Beginning Year 1} & \multicolumn{2}{|c|}{ End Year 3} \\
\hline & & 7 & $44 \%$ & 15 & $94 \%$ \\
\hline & No & 3 & $19 \%$ & & \\
\hline & With difficulty & 6 & $37 \%$ & 1 & $6 \%$ \\
\hline \multirow[t]{3}{*}{ Using a public telephone } & Yes & 11 & $69 \%$ & 16 & $100 \%$ \\
\hline & No & 2 & $12 \%$ & & \\
\hline & With difficulty & 3 & $19 \%$ & & \\
\hline \multirow[t]{3}{*}{ Knowledge of personal details } & Yes & 11 & $69 \%$ & 16 & $100 \%$ \\
\hline & No & 5 & $31 \%$ & - & - \\
\hline & With difficulty & - & - & - & - \\
\hline \multirow[t]{3}{*}{ Use of money } & Yes & 2 & $2 \%$ & 13 & $81 \%$ \\
\hline & No & 4 & $25 \%$ & & \\
\hline & With difficulty & 10 & $62 \%$ & 3 & $19 \%$ \\
\hline \multicolumn{2}{|c|}{ Asking information from strangers Yes } & 7 & $44 \%$ & 14 & $87 \%$ \\
\hline & No & 5 & $31 \%$ & & \\
\hline & With difficulty & 4 & $25 \%$ & 2 & $12 \%$ \\
\hline
\end{tabular}

Table 1 shows the data regarding the path taken by youngsters who have completed the first cycle of the three year course.

As can be seen, apart from the various differences, all the youngsters exhibit change. All are now able to cross roads by themselves, use a public telephone, ask information in order to resolve their difficulties and, apart from a little uncertainty, all know how to go shopping for minor items. Furthermore, there are aspects of each youngsters personality, such as confidence in himself, self-esteem, and the capacity to establish relations with others, which have undergone great changes in the direction of a greater knowledge and structural development of their own identities, first and foremost as adolescents, and then as adolescents with certain limitations but nevertheless as adolescents able to do a wide variety of things.

Identity is also constructed through relationships with tasks and with others, and the requests and relationships developed in these years have made an important contribution.

This has made it possible for us together with the youngsters to consider being a person with Down syndrome which, conducted through particularly "active" procedures, made it possible for us to verify their understanding of this condition and the difficulties that it led to. It also enabled us to bring out the positive aspects of the young people, the things that they knew and could do notwithstanding their condition.

\section{Conclusions}

Beyond the specific context in which these experiences have been conducted - an association of families - the programme constitutes a valuable stimulus for thought to whoever operates with persons affected by Down syndrome and more generally with persons with developmental disability.

From the point of view of the analysis of the capacity of such persons, our experience illustrates that there are still many unexplored possibilities for development, even for teenagers and young adults, and furthermore, that the ambit of social participation offers stimuli and opportunities for further growth.

From the methodological point of view, the experience as presented, offers indications for the organisation of educational actions which can be included in many environments, the family, the school, professional training, free-time, work but the urgent need for such action can no longer be ignored.

From the point of view of the objectives of an educational project for persons with disabilities, it has shown that the growth of the autonomy should proceed in the direction of integration, understood as the capacity to make use of that which is already known as well as that which is not known. Autonomy is not a matter of doing everything by oneself; it is knowing how to collaborate, ask and put information together.

In order to proceed in this direction it is necessary to exalt the value of the individual, sustain his dignity and recognise his coming of age.

Today educational courses for the acquisition of autonomy are given not only in Rome but also in 
other cities (Oristano, Pisa, Viterbo, Formia, Bari, Avellino, Reggio Calabria, Milano, Teramo, Campobasso ) and as regards the methodology of the course various application have been made in the context of public and private services all of which making use of AIPD consultancy.

The experience of the course has given rise to other projects in which people with Down syndrome figure as protagonists of their future: free-time agencies, Casapiÿ (an experience of living on one's own), inclusion in work training projects.

However, besides the positive results which have been obtained with and for people with Down syndrome, we also came to understand that the course helped modify the image that people in general held of persons with Down syndrome: the shopkeepers in the district where for the first time the experiment was conducted have today a quite different attitude towards Down persons when they enter into their shops. They have learned to understand and wait, and to attempt to understand the desires of the person in front of them. They have learned to understand him as a Person.

In order to make the course known and reproducible, the team which developed it has also published a book on the course (A. Contardi, "Libertà possibile" [the freedom possible] publisher, La Nuova Italia Scientifica) and produced a promotional video, "Ragazzi in gamba" [Clever kids].

Note: From a paper presented in October 1997, at The 6th World Congress on Down Syndrome, Madrid, Spain.

\section{Correspondence}

A. Contardi. Social Worker. Associazione Italiana Persone Down. Viale delle Milizie 10600192. Rome. Italy. Telephone/fax: +396372 2510

E-mail: aipd@flashnet.it 